\title{
Conception of a Web Operation System for Processing Petroleum Related Drilling Data: A Focus on Pre-Salt Real-Time Automation and Optimization
}

\author{
Yuri Soares Pinheiro ${ }^{*}$, Lucas Campos Vieira ${ }^{2}$, Andreas Nascimento ${ }^{1,3,4^{*} \text {, }}$ \\ Francisco de Assis Souza dos Santos ${ }^{2}$, Mauro Hugo Mathias5, \\ Gerhard Thonhauser ${ }^{3}$, Asad Elmgerbi ${ }^{3}$, Julian Hunt ${ }^{4}$ \\ ${ }^{1}$ Department of Engineering and Technology, Petroleum Engineering Programs, Universidade Federal do Espirito Santo \\ (UFES/DETEC), Sao Mateus, Brazil \\ ${ }^{2}$ Department of Computational and Electronics, Universidade Federal do Espirito Santo (UFES/DCEL), Sao Mateus, Brazil \\ ${ }^{3}$ Department of Petroleum Engineering, Chair of Drilling and Completion Engineering, Montanuniversität Leoben \\ (MUL/DPE/CDC), Leoben, Austria \\ ${ }^{4}$ International Institute of Applied System Analysis (IIASA/ASA-ENE), Laxenburg, Austria \\ ${ }^{5}$ Mechanic Department, Faculty of Engineering, Universidade Estadual Paulista (UNESP/FEG-DME/PRH48-ANP), \\ Guaratingueta, Brazil \\ Email: *yurisoarespinheiro@gmail.com, ^andreas.nascimento@gmail.com
}

How to cite this paper: Pinheiro, Y.S. Vieira, L.C., Nascimento, A., de Assis Souza dos Santos, F., Mathias, M.H., Thonhauser, G., Elmgerbi, A. and Hunt, J. (2019) Conception of a Web Operation System for Processing Petroleum Related Drilling Data: A Focus on Pre-Salt Real-Time Automation and Optimization. Journal of Software Engineering and Applications, 12, 61-71. https://doi.org/10.4236/jsea.2019.124005

Received: January 17, 2019

Accepted: April 7, 2019

Published: April 10, 2019

Copyright () 2019 by author(s) and Scientific Research Publishing Inc. This work is licensed under the Creative Commons Attribution-NonCommercial International License (CC BY-NC 4.0). http://creativecommons.org/licenses/by-nc/4.0/ c) (i) (8) Open Access

\begin{abstract}
Petroleum and Natural Gas still represent a considerable share in terms of energy consumption in the current global matrix, so that its exploration/exploitation is present in the market and driving activities in locations of specific complexities, as the ones along unconventional hydrocarbon resources from the Brazilian pre-salt. The daily cost of well drilling under harsh conditions can exceed US $\$ 1$ million a day, turning any type of downtime or necessary maintenance during the activities to be very costly, moment in which processes optimization starts to be a key factor in costs reduction. Thus, new technologies and methods in terms of automating and optimizing the processes may be of great advantages, having its impact in total related project costs. In this context, the goal of this research is to allow a computation tool supporting achieving a more efficient drilling process, by means of drilling mechanics parameters choosiness aiming rate of penetration (ROP) maximization and mechanic specific energy (MSE) minimization. Conceptually, driven by the pre-operational drilling test curve trends, the proposed system allows it to be performed with less human influences and being updateable automatically, allowing more precision and time reduction by selecting optimum parame-
\end{abstract}


ters. A Web Operating System (Web OS) was designed and implemented, running in online servers, granting accessibility to it with any device that has a browser and internet connection. It allows processing the drilling parameters supplied and feed into it, issuing outcomes with optimum values in a faster and precise way, allowing reducing operating time.

\section{Keywords}

Trend Curves, Web OS, Optimization, Pre-Salt, Petroleum

\section{Introduction}

Petroleum and Natural Gas still represent a considerable share in terms of energy consumption in the current global matrix, so that its exploration/exploitation is present in the market and driving activities in locations of specific complexities, as the ones along unconventional hydrocarbon resources from the Brazilian Pre-salt [1] [2]. The daily cost of well drilling under harsh conditions can exceed US \$1 million a day, turning any type of downtime or necessary maintenance during the activities to be very costly, moment in which processes optimization starts to be a key factor in costs reduction. Thus, new technologies and methods in terms of automating and optimizing the processes may be of great advantages, having its impact in total related project costs.

Throughout the process of drilling a specific well, data are collected detailing the operation, and by some specific task performed, such as pre-operational drilling tests, generally, the data are interpreted in a superficial way, requiring manually to identify best conditions for drilling. Aiming using optimum drilling parameters, currently, the drill-rate tests are performed along analysis with different combination of rotational speed (not always) and weigh-on-bit (most common), so that these tests are not run in exhaustive modus, enabling all combination to be tested, but just partially performed as more qualitative tool orientation [3]. After the test is finished, results should allow selecting a set of drilling mechanics parameters that enables highest rate of penetration (ROP) for a given well section [4]. This test is done aiming "optimization" of the drilling rate and thus, reducing the operating time, resulting in cost savings. A drilling activity in the Brazilian Pre-salt field can reach around US \$1.3 million as a daily cost [5], which makes the proposed computational tool presented in this paper very appropriate for this scenario.

In a direct approach, by making use of the developed system, one can have drilling data treated live, showing to the operators or even service companies' reference of values allowing an optimum operation. In addition, the data processing of the drill-rate test is done in a global way, which does not always reflect in a more specific situation, where the parameters that are not controllable can change over time and depth. In this configuration, the proposed computational tool developed by [3], in MATLAB, presents the optimal values for the 
highest ROP taking into consideration the controllable parameters and thus presenting values that contrast with the optimum values visualized for the global measurements, which would make the process more efficient and then less costly. The drawback in that are the restrictions to MATLAB, which do not allow slow processing computers and devices, such as smartphones or tablets, to see results smoothly and fast.

Moreover, programs and systems can be maintained in a cloud, where large amount of information can be processed online. Serving with a more robust processing, this methodology by means of Web OS application showed to be positive and then has been further developed as detailed throughout this paper [3].

\section{Methodology and Components}

An initial survey about the demand to be addressed with the related petroleum drilling activities and data was conducted through interviews with engineers, operators and managers from different position. It was identified that the predominant approach in the field is subject to estimates, with only drilling initial information and not automatized. Faced with the potential benefits of a web operation system for the processing of drilling data, efforts were applied in modeling and implementing the specific computational tool here trough presented.

A literature review was conducted to retrieve the main methods and components of software engineering. In this analysis were used mainly the following databases: Elsevier, Scielo, IEEE Xplore, OnePetro and JSEA, applying the key terms: Software Modeling, Unified Modeling Language, Petroleum Systems.

Based on that and related analysis outcomes, it was possible to understand the relevance of software modeling and the need to use the Unified Modeling Language (UML) in the present work. The modeling of the proposed web system was performed including class diagrams, use cases diagram and sequence diagram. The choice of these three UML diagrams is supported by their relevance and considered, by consensus from the literature, to be the main important ones for what it is proposed. Regarding database, the Entity Relation Diagram was used, since it is a reference for database architectures development.

The final test and simulation were performed making use of Brazilian Pre-salt data, main driver for the developed idea, since operations in these fields have been very costly due to low rate of penetration achievement during the drilling operations.

\subsection{Software Modeling: UML Diagrams}

Computational systems, as well as any other type of related projects, has importance directed to first steps in having it well detailed and structured, so that all its design is planned in such a way to allow maintenances or future increments. For the current work, Unified Modeling Language (UML) was used in order to parameterize functionalities, structures and programming objects. UML is a very 
broad scope covering a large set of application domains, which can have 13 (thirteen) varieties for model development [6]. And for a Web-based System modelling, it is proposed to use some specifies such as: Use Case Diagram, Class Diagram and Sequence Diagram [5]. In this context, these have been the main reference for developing it, having the related database modeled with Entity Relation Diagram (ERD).

\subsubsection{Use Case Diagram}

The Use Case Diagram define the functionality of the system in the user's perspective, representing its boundaries, also detailing the complexity of the system [5]. Figure 1 details the representation of the system by the user and administrator's view, being the administrator functionalities to maintain the platform control over open registered information and user control. The input and process of the data access are reserved to the registered system users. All the functionalities represented in the use case diagram are inherent to the system.

\subsubsection{Class Diagram}

The Class Diagram allows modeling a static system view, which is considerably important for object-oriented systems modelling and design, representing the multiplicity relationships between the different classes among the scheme [5] [6] [7]. Figure 2 details the Class Diagram representing the classes attributes, relations and associations to be used inside the developed platform.

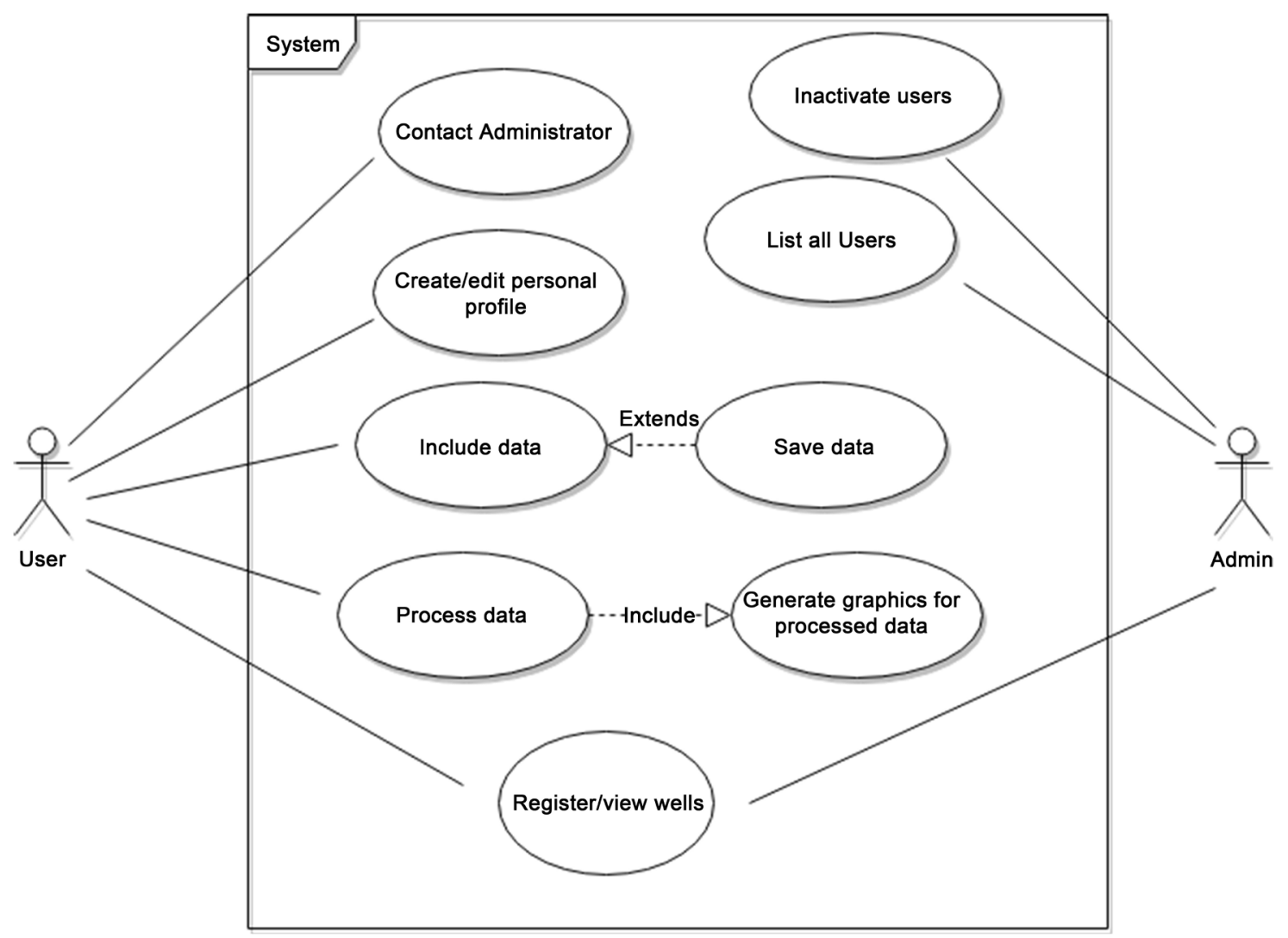

Figure 1. End user and administrator use case diagram. 


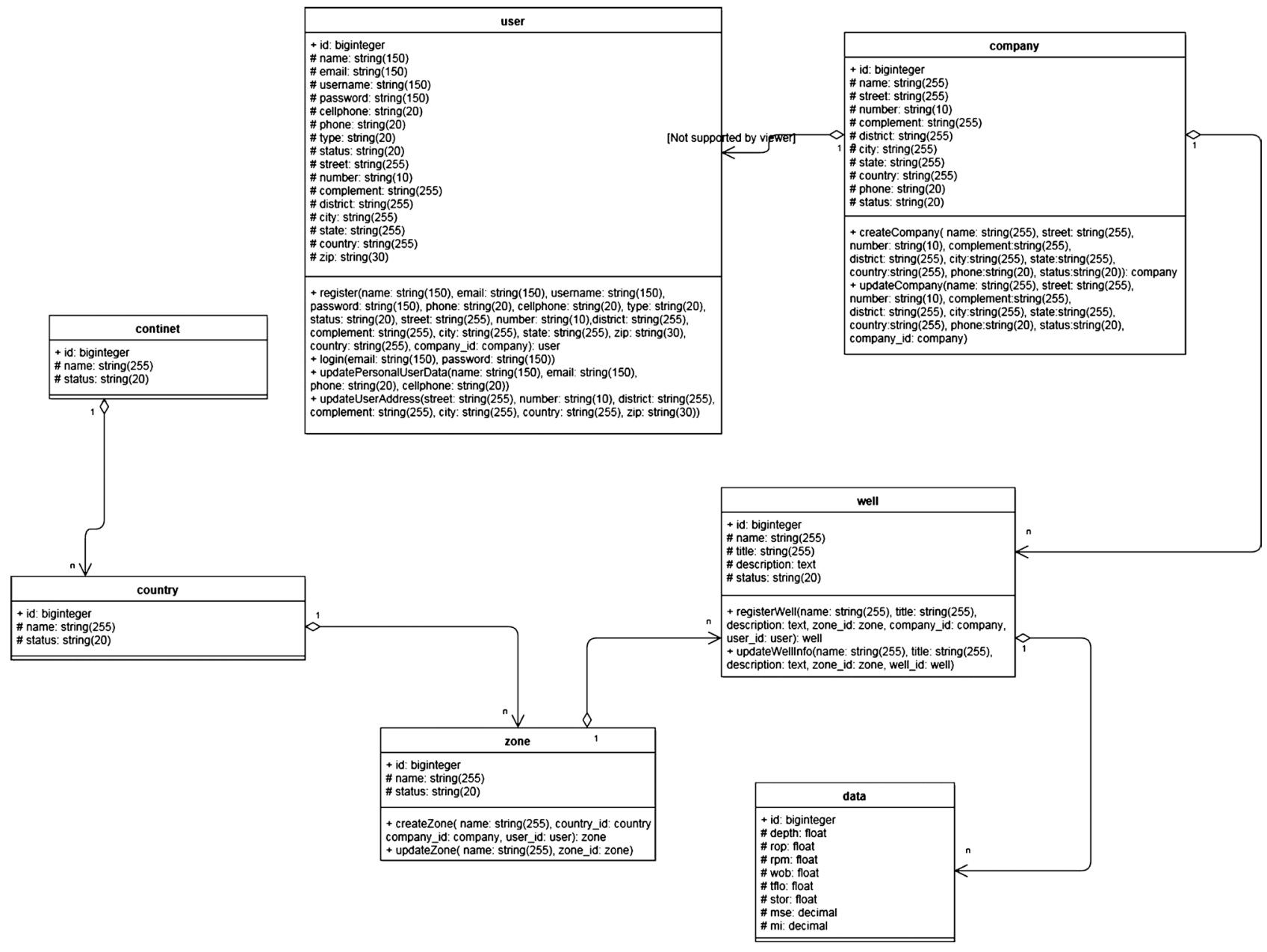

Figure 2. Web system class diagram.

\subsubsection{Sequence Diagram}

The Sequence Diagram represents the flow of the events, messages and interactions between the objects of a system in two dimensions in play [5]-[11]. Figure 3 represents details in terms of system's functionalities responding to End User's requests.

\subsection{Entity Relation Diagram}

The process of modelling the whole system (Figure 4 and Figure 5) consists in not just describing classes, its relations, user's perspectives of the system and the behavior of its internal structures, but it is necessary to have the database designed, performed using the Entity Relation Diagram (ERD) supportive tool. This type of diagram represents the database tables and relations, graphically (Figure 6).

\section{Results}

\section{System Design}

The Web OS design was divided into two parts. The first is linked to feedback collection in terms of design development and system understanding, being all 
Sequence Diagram User-Platform

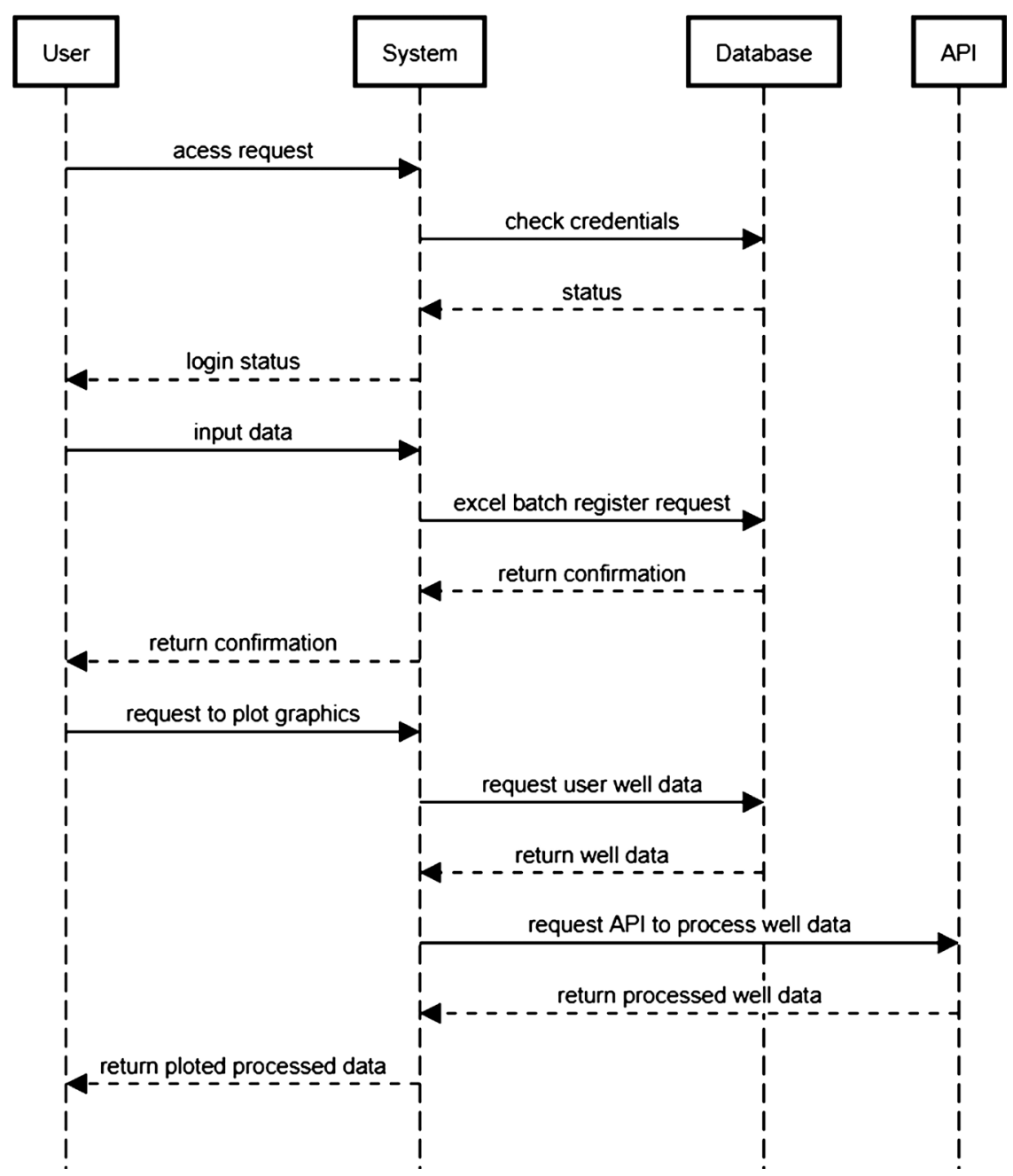

Figure 3. Sequence Diagram representation End Users action and processing data (input, saving, processing, and post-processing).

developed by hand with sequentially digitalization with the Balsamiq Web-based Software, for the wireframe development (Balsamiq Studios-LLC). The Second part was to get these developed wireframe designs and use them as base to develop a computational tool in HTML5, CSS3 and JavaScript supportive languages, with some elements of PHP 7.0 (necessary to allow communication with the backend).

With the second part already implemented, all the processing data can be seen in live, with the parameters changing dot by dot as in the operation, allowed through a dataset simulation, with a global overview of the best parameters choosiness (Figure 4), for weight-on-bit (WOB) versus Mechanical Specific Energy (MSE) and versus Rate Of Penetration (ROP).

\section{Conclusion}

The implementation of this platform brought an updated solution with the current 


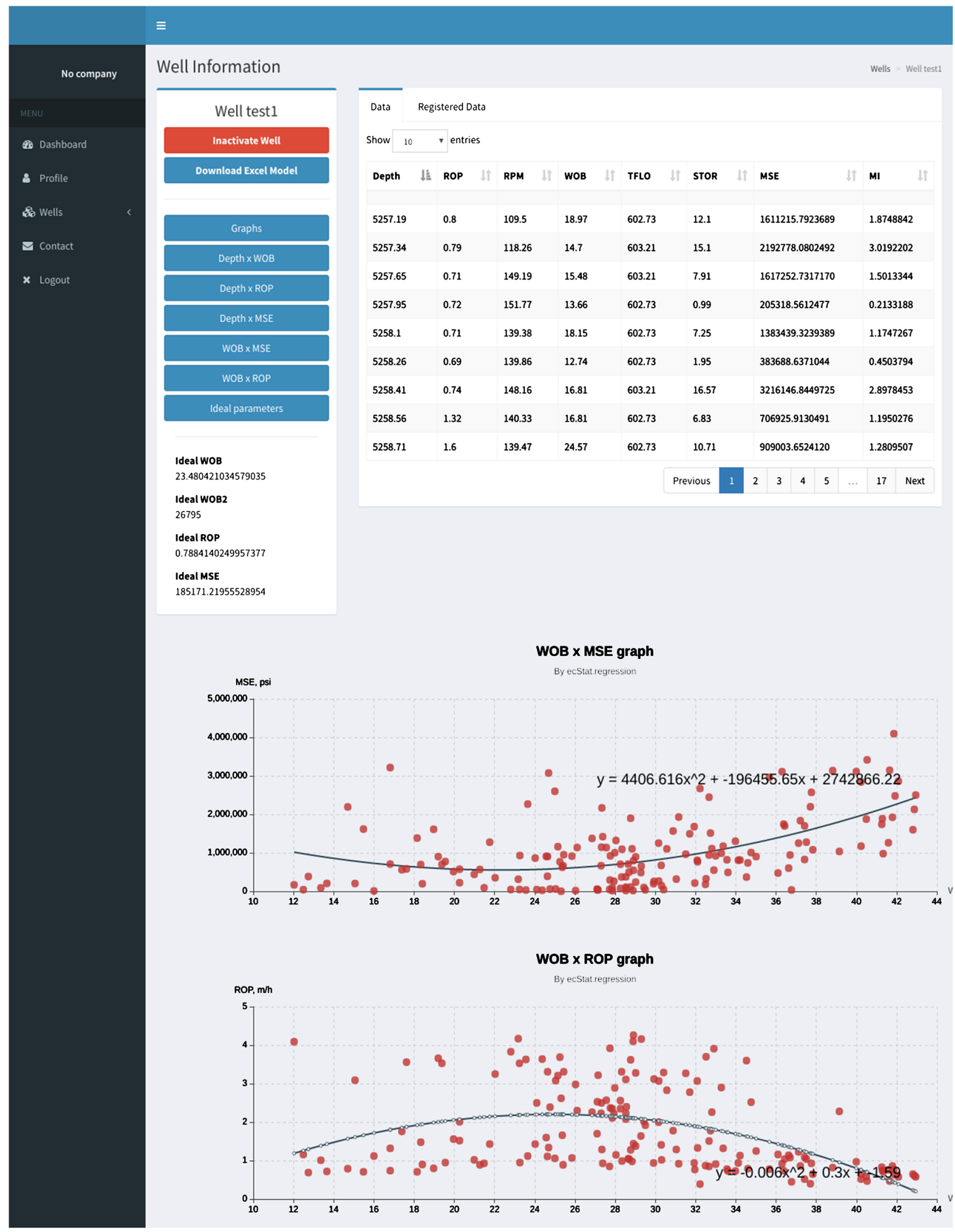

Figure 4. Page where the processing of data happens, showing ideal parameters and trend curves with two different graphs, accounting for MSE and ROP respectively. 


\section{Depth $\times$ WOB}

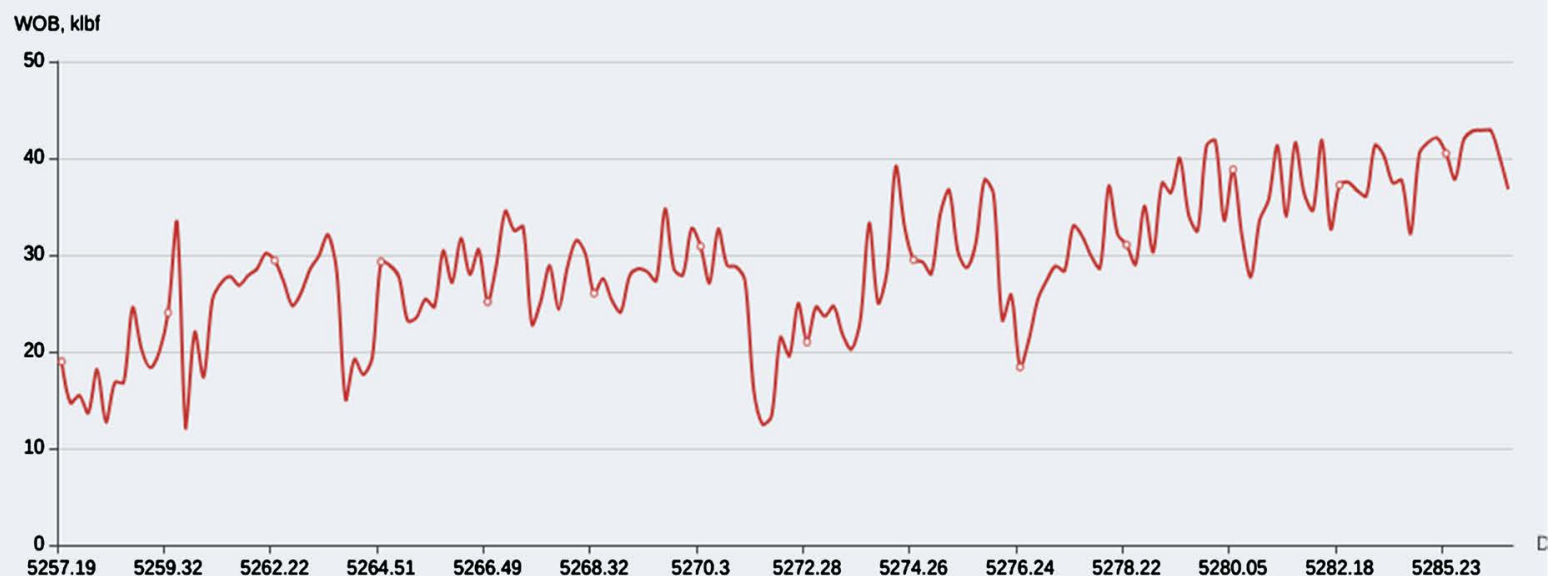

\section{Depth $\times$ ROP}

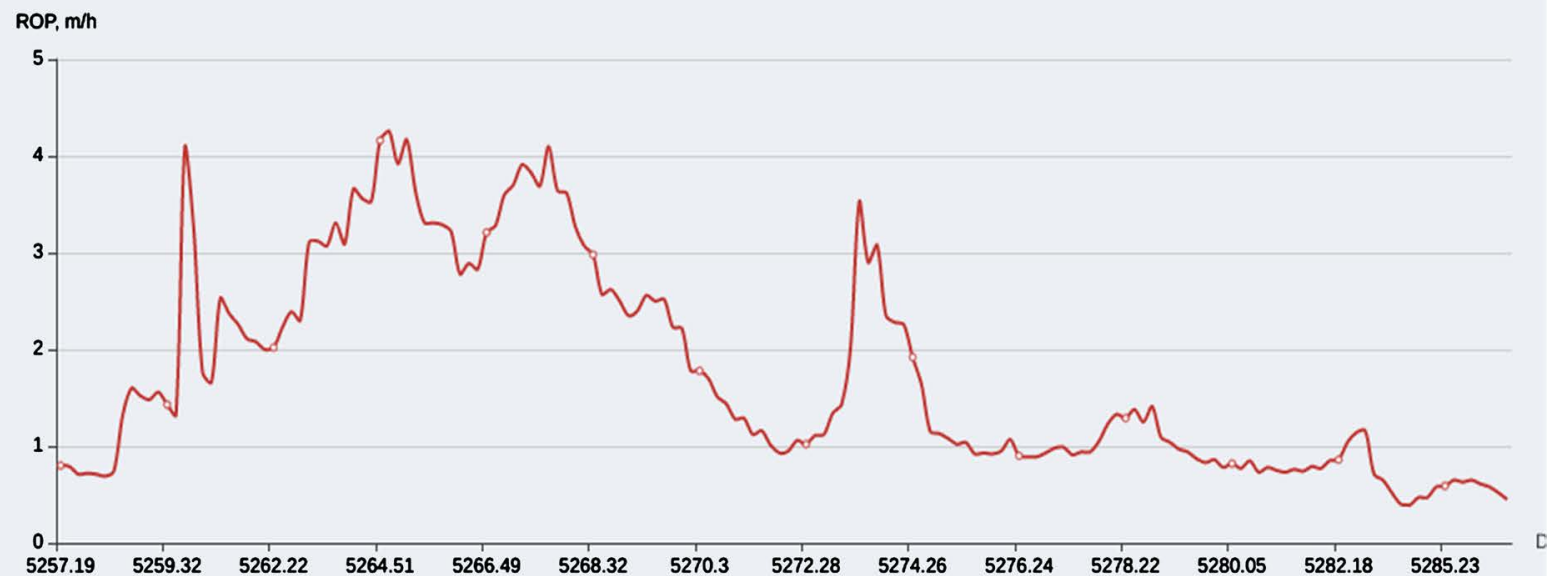

\section{Depth $\times$ MSE}

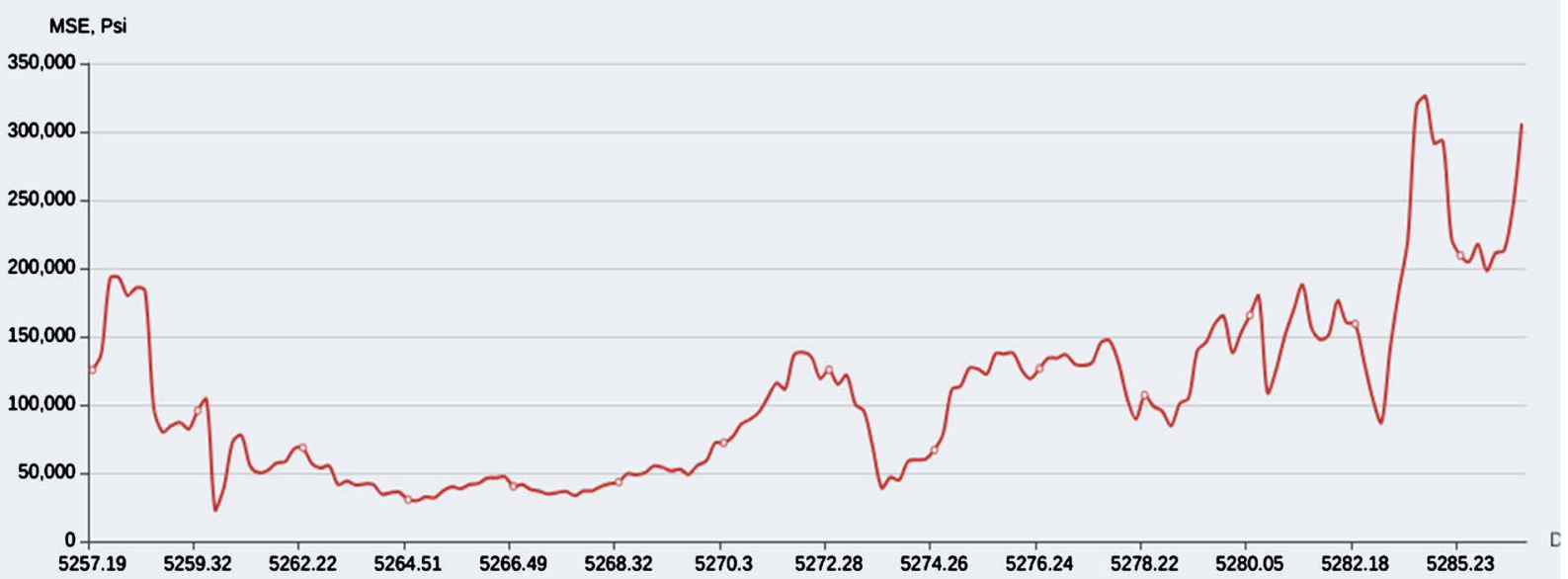

\section{Copyright @ 2018. Todos os direitos reservados}

Figure 5. Second part of the system, showing the general graph-view where data can be analyzed with generated optimum graphs and optimum parameters. 


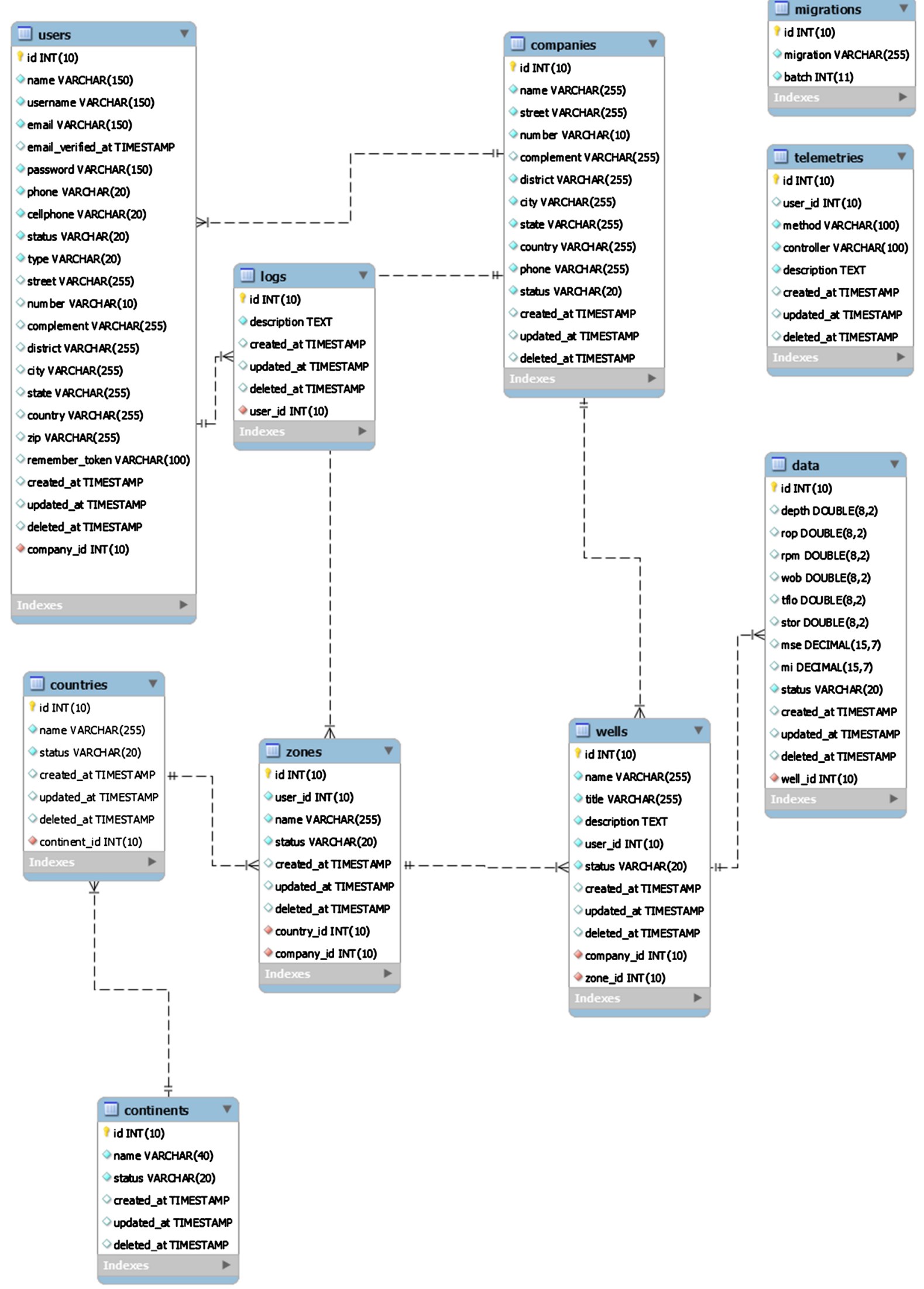

Figure 6. Entity Relationship Diagram (ERD) with the system database details. 
available resources, such as the use of servers, which allows localized processing of information obtained in the field, in one place, and live update and visualization in the results by any device with internet connection with a browser. This online implementation allows a greater dynamicity with respect to the application in the industry, which will make possible a greater use by companies, enabling the use of this drilling optimization software. In order to achieve the expected results, from a software engineering perspective, adequate modeling of the software and database is necessary. This will contribute to data integrity, maintainability and readability of software code.

\section{Acknowledgements}

The authors would like to thank CAPES (call 24/2017-IIASA), FAPES (call 03/2017-UNIVERSAL), ANP, UFES, PRH48-ANP/UNESP and DPE/MUL-Austria for the support with the current research.

\section{Conflicts of Interest}

The authors declare no conflicts of interest regarding the publication of this paper.

\section{References}

[1] Nascimento, A., Bortoni, C., Edson, D.A., Gonçalves, J.L., Duarte, P.A. and Mathias, M.H. (2015) Single-Phase Velocity Determination Based in Video and Sub-Images Processing: An Optical Flow Method Implemented with Support of a Programmed MatLab Structured Script. Journal of Software Engineering and Applications, 8, 290-294. https://doi.org/10.4236/jsea.2015.86029

[2] Nascimento, A., Kutas, D.T., Elmgerbi, A., Thonhauser, G. and Mathias, M.H. (2015) Mathematical Modeling Applied to Drilling Engineering: An Application of Bourgoyne and Young ROP Model to a Presalt Case Study. Mathematical Problems in Engineering, 2015, Article ID: 631290. https://doi.org/10.1155/2015/631290

[3] Feitosa, B. da C. and Nascimento, A. (2017) Proposta de metodologia para otimização da perfuração da camada pré-sal utilizando drill-rate test automatizado e dinâmico.

[4] Souto, T.C. and Nascimento, A. (2017) Metodologia para Otimização da Perfuração aplicada ao Pré-Sal: Análise através da Energia Mecânica Específica. Latin American Journal of Energy Research, 1-15.

[5] Nascimento, A., Elmgerbi, A., Roohi, A., Prohaska, M., Thonhauser, G., Goncalves, J.L. and Mathias, M.H. (2016) Reverse Engineering: A New Well Monitoring and Analysis Methodology Approaching Playing-Back Drill-Rate Tests in Real-Time for Drilling Optimization. Journal of Energy Resources Technology, 1, 30.

[6] OMG (2007) UML 2.4.2 Superstructure Object Management Group.

[7] Erickson, J. and Keng, S. (2007) Can UML Be Simplified? Practitioner Use of UML in Separate Domains.

[8] Alhumaidan, F. (2012) A Critical Analysis and Treatment of Important UML Diagrams Enhancing Modeling Power. Intelligent Information Management, 4, 231-237.

[9] Ali, R. (2017) Design and Implementation of Mobile Portal for Kenyan Pastoralists. Journal of Software Engineering and Applications, 10, 884-890. 
https://doi.org/10.4236/jsea.2017.1012050

[10] Gazzoli, A.S. and Nascimento, A. (2017) Análise da semelhança entre as curvas de drill-rate test com as curvas de tendência geradas a partir dos dados de perfuração e vantagens em aplicá-las de forma dinâmica.

[11] Somé, S. and Anthonysamy, P. (2009) An Aspect-Oriented Approach for Use Case Based Modeling of Software Product Lines. Journal of Software Engineering and Applications, 2, 248-258. https://doi.org/10.4236/jsea.2009.24032 